\title{
Topical capsaicin cream was effective for chronic idiopathic intractable pruritis ani
}

Lysy J, Sistiery-Ittah M, Israelit $Y$, et al. Topical capsaicin-a novel and effective treatment for idiopathic intractable pruritus ani: a randomised, placebo controlled, crossover study. Gut 2003;52:1323-6.

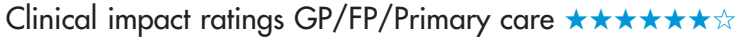

In patients with chronic idiopathic intractable pruritus ani, what is the effectiveness of topical capsaicin?

\section{METHODS}

L

Design: randomised, placebo controlled, crossover trial

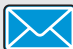

Allocation: concealed. *

Blinding: blinded (patients and healthcare providers).*

Follow up period: 4 and 9 weeks.

Setting: proctological outpatient clinics in a hospital and affiliated ambulatory clinic in Jerusalem, Israel.

Patients: 44 patients (mean age 50 y, 55\% women) who had chronic idiopathic anal itching for $\geqslant 3$ months that had not responded to traditional treatment.

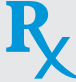

Intervention: a thin layer of perianal topical capsaicin cream, $0.006 \% 3$ times each day for 4 weeks $(n=22)$ or menthol cream $1 \%$ (placebo) $(n=22)$. After a 1 week washout period, patients received the alternative treatment for 4 weeks. No patients received topical steroids or anaesthetics during the study.

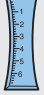

Outcomes: clinical response (itching scores of $1=$ no symptoms or 2 = nearly complete symptomatic relief with sporadic episodes of mild itching; scores of 3-5 were classified as negative responses) and side effects (burning sensation after application, scored from 1-5) based on data collected in daily patient symptom diaries.

$\square \square$ Patient follow up: all patients were included in the analysis. *See glossary.

Capsaicin $v$ placebo for chronic idiopathic intractable pruritus ani*

\begin{tabular}{|c|c|c|c|c|}
\hline Outcomes & Capsaicin & Placebo & $\begin{array}{l}\text { Mean } \\
\text { difference }\end{array}$ & p Value \\
\hline $\begin{array}{l}\text { Mean clinical response } \\
\text { score at } 4 \text { weeks } \dagger\end{array}$ & 187 & 4.42 & -2.55 & $<0.001$ \\
\hline $\begin{array}{l}\text { Mean burning sensation } \\
\text { score } †\end{array}$ & 2.60 & 2.24 & 0.36 & $<0.001$ \\
\hline Duration of burning (min) & 14.64 & 12.02 & 2.62 & $<0.001$ \\
\hline
\end{tabular}

*Scores ranged from 1 (no symptoms) to 5 (maximum symptoms)

For correspondence: Dr E Goldin, Hadassah University Hospital, Jerusalem, Israel.goldin@cc.huji.ac.il

Source of funding: no external funding.

\section{MAIN RESULTS}

Clinical response to capsaicin was better than to placebo (McNemar test $\mathrm{p}<0.0001)$. 31 of 44 patients had a clinical response during capsaicin treatment and did not respond to placebo; all patients not responding to capsaicin also did not respond to placebo. Capsaicin treatment was associated with lower itching scores than placebo but led to higher burning sensation scores and a longer duration of burning after application (table). 3 patients in the capsaicin group dropped out of the study because of moderate to severe perianal burning.

\section{CONCLUSIONS}

Capsaicin cream was effective for chronic idiopathic intractable pruritis ani but was associated with an increased, but generally short duration, burning sensation after application. For most patients, the increased burning after application was not severe enough to cause withdrawal from the study.

\section{Commentory}

tching of the perianal skin can cause extraordinary annoyance and embarrassment. Known or putative causes include faecal soilage, dietary irritants, anorectal disorders such as haemorrhoids or malignancies, dermatological conditions, and infections. Attention to these conditions, use of appropriate hygiene, and judicious use of short courses of topical hydrocortisone will help about $90 \%$ of people with anal itch. ${ }^{1} 10 \%$, however, will be left in unexplained and intractable misery. Until now their options have been few, although some have gained relief after destruction of dermal nerve endings through local injection of methylene blue. ${ }^{2}$

Lysy et al report a short term study showing that topical capsaicin can be an effective treatment for intractable pruritus ani. Blinding was facilitated by the use of a menthol "placebo," which caused burning but had no antipruritic benefit. The results were encouraging, with 31 of 44 participants experiencing total or substantial relief. 29 participants chose to continue open label use of capsaicin for 10.9 months, and they remained symptom free, or nearly so, with an average of just 1 daily application.

Capsaicin blocks the action of $\mathrm{C}$ nerve fibres through depletion of substance P. Usually dispensed in $0.025 \%$ concentrations, its use as a topical antipruritic has been limited by its provocation of burning, with $30 \%$ of users unable to continue treatment. ${ }^{3}$ Lysy et al used a much lower dose, $0.006 \%$, and found that only 4 of 44 patients were unable to tolerate that concentration. For most patients, burning was mild and brief and decreased with repeated use of capsaicin. For patients with intractable idiopathic pruritus ani, this novel treatment has the potential to provide welcome long term relief.

David R Gutknecht, MD Geisinger Medical Center Danville, Pennsylvania, USA

1 Daniel GL, Longo WE, Vernava AM 3rd. Pruritus ani. Causes and concerns. Dis Colon Rectum 1994;37:670-4.

2 Eusebio EB, Graham J, Mody N. Treatment of intractable pruritus ani. Dis Colon Rectum 1990:33:770-2.

3 Yosipovitch G, David M. The diagnostic and therapeutic approach to idiopathic generalized pruritus. Int J Dermatol 1999;38:881-7. 